\title{
A Brief Analysis of the Narrative Characteristics of Karwai Wong Film with "Days of Being Wild" as an Example
}

\author{
Bo Zhang, Weiqing Sun \\ Department of Film and Television Arts, Shanghai Publishing and printing College, Shanghai, China \\ Email: 309752339@qq.com
}

How to cite this paper: Zhang, B., \& Sun, W. Q. (2020). A Brief Analysis of the Narrative Characteristics of Karwai Wong Film with "Days of Being Wild" as an Example. Art and Design Review, 8, 170-175. https://doi.org/10.4236/adr.2020.83013

Received: July 8, 2020

Accepted: July 31, 2020

Published: August 3, 2020

Copyright (๑) 2020 by author(s) and Scientific Research Publishing Inc. This work is licensed under the Creative Commons Attribution International License (CC BY 4.0).

http://creativecommons.org/licenses/by/4.0/

\begin{abstract}
As a leading figure of Hong Kong film, Karwai Wong has contributed numerous outstanding works to the Chinese film circle and even the world film circle. Behind his highly abstract image world, it reflects people's bewilderment of rootless drifting in modern cities. Through the analysis of the movie "Days of Being Wild", this paper reveals the narrative characteristics of Karwai Wong film.
\end{abstract}

\section{Keywords}

Leading Figure, Rootless, Narrative Characteristics

\section{Introduction}

As a representative of melodrama movies directors in Hong Kong, Karwai Wong has his own unique style in selecting creative themes. From his first film "As Tears Go by" to "The Grandmaster", he has always maintained a balance between business and art, personal style and the requirement of audience in the 30 years of his movie career. Under the influence of the context of the new wave film and constantly breaking the boundaries of types, his films have created a film language with extremely distinctive personal characteristics by deforming, mixing and collage different types of elements (Wang, 2017). A majority of his films are related to the theme of love, including ambiguous emotions, refusal and jealousy, separation and pain. Similar emotional experiences recur in disparate film stories, and grow to mature along with the film. This paper will take Karwai Wong film "Days of Being Wild" as an example to carry out the research in terms of narrative theme, performance figures and other aspects, and show the narrative characteristics of Karwai Wong film. 


\section{Research Background}

Karwai Wong film that directed after the "new wave" movement in Hong Kong is another proactive exploration of the atmosphere and context of the times in Hong Kong. Francois Truffau, a representative of the French new wave, put forward the concept of "author movie" (Wang, 2014). In his article A Certain Tendency of the French Cinema, he first mentioned the viewpoint of "Authoritative directorship, integration of screenwriter and director". A screenwriter is like a wanderer full of imagination, while a director is an executor follows practical principles. By combining these two, the author's will is embodied in the film, forming the author movie with a unique style. Almost all of Karwai Wong's films are wrote and directed by himself, and he is practicing the path of being a "movie author".

After the First Opium War (1840-1842), Hong Kong was ruled by Britain for more than 100 years, and its culture was written by the confrontation and integration between foreign colonial culture and local culture (Fu, 2016). With the rise of the post-colonial criticism wave around the world, many countries and regions under colonial rule began to clarify their own consciousness and culture. In the anti-colonial ideological environment of the international community, Karwai Wong's creation is deeply influenced by the post-colonial criticism wave. His film works express his contemplation and reflection on Hong Kong's post-colonial situation with a positive attitude. Though the analysis of Karwai Wong film "Days of Being Wild", this paper aims to excavate the characteristics and styles of the narrative theme and characters in the film under the influence of the foreign colonial culture, the local culture and the new wave movement.

\section{Research Methods}

\section{1) Literature research method}

In order to have an in-deep understanding of the characteristics and style of Karwai Wong's works as well as his image style, the author has read a great deal of books and articles about the research of Karwai Wong's works, and collected a lot of literature about film and television narratology theory and postmodernism theory, so as to render the thesis a richer theoretical basis. Since Karwai Wong film is a banner of Hong Kong film, the author also read plenty of literature and materials about the research of Hong Kong film. Due to the intercultural communication characteristics of Karwai Wong's works, in order to more objectively evaluate the works directed by him, the author often browses foreign websites about the review of Karwai Wong film, so as to find the information conforming to my thesis research, understand the research content more accurately, quickly, comprehensively and objectively, and find problems and seek the solution to them.

\section{2) Case study}

Case study also is applied in this paper to conduct research. It selects the most representative work hitherto directed by Karwai Wong "Days of Being Wild" as 
the main case. Starting from this film, it summarizes and sorts out his narrative style and narrative strategy, so as to provide sufficient evidence for my research results. Through the analysis of the specific scenes, setting of marginal character and the motif of the film presented in "Days of Being Wild", this paper explores several elements of Karwai Wong film's success.

\section{Narrative Themes in Karwai Wong Film}

Throughout the theme of Karwai Wong film, there appears a key word: searching. His movie "Days of Being Wild" also follows this theme clue: searching. In this narrative theme, he used images such as footless bird, biological mother and tropical rain forest to metaphorize Xuzai's searching, kinship and state life. In today's society with highly developed material civilization, people are becoming increasingly alienated. Everyone will be self-enclosed and unwilling to reveal his heart to others. The extreme difficulty of communication makes the normal interpersonal relationship begin to change. The highly commercialization and the pressure of realistic survival cause indifference between people, their mental state is impetuous as well, and there is no slightest faith in their life goals. Therefore, through the presentation of such a theme, Karwai Wong carries out a kind of "introspective" expression and exhortation.

Apart from that, the theme of "searching" is also related to the political background of Hong Kong. Due to the long time of Britain colonial rule, Hong Kong people was lack of secure, they generally could not feel the stability in the transitional period, their personal life were in a state of drifting, and they were universally "rootless" psychologically. Therefore, the searching for "home" and "root" revealed in his film reflects the feature of Hong Kong in Karwai Wong film in a way.

\section{The Narrative Characters in Karwai Wong Film}

Karwai Wong's films have always been very concise in character arrangement. There are not many presences of characters in each film, sometimes, some characters do not really appear, some are just the appearance of voices. His processing method is called "the absence of characters" by some people (Qin \& Chen, 2012). Deeply influenced by the theory of "author movie", Karwai Wong's works pay special attention to and ponder over the existence of human beings. The majority of the characters in his films are drifting and lonely. The are reticent with vague identity and walk on the edge of society, but they often present some contradictory characteristics. The male characters in Karwai Wong's films have complex characteristics.

The characters in Wang Jiawei's films give Hong Kong a narcissistic stubbornness, connecting the lost history and anxious modern times and digging into what modern Hong Kong people want to express but try to hide in fragmented collage scenes, which is seemingly careless, but carefully carved out the wandering confused form of Hong Kong people for a long time, who want to 
beyond the history, but to find a position in the history with nostalgic mood inevitably, try to communicate with people, but fear of being hurt, and can only unconsciously expressing the desire for warmth and stability, forming a representative of Hong Kong people in a new era, characters such as A Fei created by Wang Jiawei. There are few meaningful names in Wang Jiawei's films, but "A Fei" is a name with fable meaning, which is the finishing touch of Wang Jiawei's creation. "Fei" means above the ground, means seeking and pursuing, means drifting and migrating. A Fei's fate also shows that when he wants to settle down on a certain coordinates, but found himself a footless bird, so the mentality of the new generation of Hong Kong people can be summed up as "rootless" (Lin, 2018).

In this film, the protagonist, Fei, is a Shanghai immigrant who was abandoned as a child by his mother and raised by his adoptive mother. Due to his emotional deficiency, he had a special feeling for women with both love and hate. The great thing about the world of light and shadow used by Wong Kar-Wai is that he has a unique way of explaining his own philosophy and rules of cinema, while also mercilessly reveals the pains that everyone is unwilling to reach, thus showing the modern man's sense of wandering and the pessimistic fatalism of life's pursuits is a constant theme in Wong Kar-Wai's films.

In Wong Kar-Wai's films, the female professional identity corresponding to male characters is usually that of a dancer, a shopkeeper, a playgirl, a hitwoman, and other socially inferior or marginalized women's identities, which on the one hand represent a certain symbolic value, and on the other hand can enhance the viability of the stories. From a narrative point of view, Wong Kar-Wai's films take men as the main narrative subject, while women are more of a kind of "being seen" aesthetic object. While satisfying the male perspective, what we see more from it is the rejection of men, women's frustration and misery that comes with rejection, women seem doomed to endure the miserable rain and wind because they can't get out of the net of male-dominated discourse, and in the midst of the miserable rain and wind, the flowers bloom from the drifting water flows on its own. Su Lizhen was an introverted person, lived her life carefully, placed her emotions carefully, and always obeyed the rules. Before meeting Fei, she always believed that she would just settle down and go on. The youthful Maggie Cheung played the role of Su Lizhen with more innocence and less mature. The slight upturn of the lip in her sleep destined for her uncontrollable fall. Su Lizhen is the model of a traditional Chinese woman, conservative, gentle and simple.

On the whole, the unique narrative style of Karwai Wong's films stems from his grasp and expression of the characters' emotion, spirit and temperament. By deliberately downplaying the development of the story and the dramatic conflict, he put emphasis on the character shaping. There is a paranoid theme in his films, namely "people-to-people communication". It is the narrative power of his films to show the characters' state of life and ideological changes. Consequently, it is of great value to explore the characters in Karwai Wong's films. 


\section{Conclusion}

Director Karwai Wong is a film "author" with his own artistic style. In this film kingdom with numerous masters and endless works, he has constructed his own original film language system through incessant innovation and attempt of film language. This individual artistic style and expression method enable him have a place on the international arena.

Generally speaking, through the analysis of the historical background, the theme presented and the character shaping in Karwai Wong's film, we can draw a conclusion that "searching" is the principle and characteristic that he always follows in his film creation, and this feature originates more from Hong Kong's rootless culture. As a British colony, Hong Kong incessantly expresses its exclamation for history and memory, and it also penetrates with the sense of identity that Hong Kong people yearned for all the time. Therefore, in his later works, he continued to explore and pursue in this way. Karwai Wong's films with the characteristics of "searching" have strong cultural and social values. In addition to a unique artistic temperament, his films reveal the connotation of oriental aesthetics, and organically combine the western post-modern thoughts with the traditionally introverted oriental characteristics, which not only make the Eastern characteristics more prominent in the film, but also skillfully balances its artistic and commercial nature (Wei \& Li, 2013). Apart from adhering to his paranoid theme, it continuously absorbs and applies the expression of the new era. Through such a feature, Karwai Wong cultivates the commercial value and artistic value of his films. Of course, classic films should be better integrated into the technology of the industry. In the future, Karwai Wong's films can be presented with virtual reality technology.

\section{Acknowledgements}

This work was funded by the 2019 Shanghai Art Science Planning Project, "Research on the Application of Narrative Virtual Reality (VR) Art in Shanghai Museum", project number: YB2019C02.

\section{Conflicts of Interest}

The authors declare no conflicts of interest regarding the publication of this paper.

\section{References}

Fu, L. (2016). Karwai Wong's Film Aesthetics: From the Perspective of Aestheticization of Everyday Life. Science \& Technology for China's Mass Media, No. 6, 232-234.

Lin, C. C. (2018). On Hong Kong New Wave Cinema. Chinese Literature, No. 3, 84-92.

Qin, Y., \& Chen, H. Z. (2012). Pseudo Art and Real Business: The Performance Strategy of Karwai Wong Film in the Commercial Context. Film Review, No. 20, 1-3.

Wang, D. L. (2014). Artistic Color and Personality Characteristics of Karwai Wong Film Music. Film Literature, No. 4, 36-39. 
Wang, L. (2017). Karwai Wong Film from the Perspective of "Author Movie" Theory (No. 7, 32-34). Taiyuan: Shanxi University.

Wei, C. J., \& Li, J. W. (2013). The Grandmaster: New Thinking of Kung Fu and Postmodern Examination. Film Review, No. 17, pages. 